\title{
Synthesis and Antibacterial Testing of Silver/Poly (Ether Amide) Composite Nanofibers with Ultralow Silver Content
}

\author{
Shuai Liang, ${ }^{1}$ Geng Zhang, ${ }^{2}$ Jianzhong Min, ${ }^{1}$ Junqiao Ding, ${ }^{3}$ and Xingmao Jiang ${ }^{1,4}$ \\ ${ }^{1}$ Key Laboratory of Fine Petrochemical Engineering, Changzhou University, Changzhou 213164, China \\ ${ }^{2}$ Department of Chemistry, College of Science, Huazhong Agricultural University, Wuhan 430070, China \\ ${ }^{3}$ State Key Laboratory of Polymer Physics and Chemistry, Changchun Institute of Applied Chemistry, \\ Chinese Academy of Sciences, Changchun 130022, China \\ ${ }^{4}$ Changzhou Yingzhong Nano Technology Company Limited, Changzhou 213023, China \\ Correspondence should be addressed to Xingmao Jiang; jxm@cczu.edu.cn
}

Received 1 April 2014; Revised 17 July 2014; Accepted 17 July 2014; Published 11 August 2014

Academic Editor: Tianxi Liu

Copyright (c) 2014 Shuai Liang et al. This is an open access article distributed under the Creative Commons Attribution License, which permits unrestricted use, distribution, and reproduction in any medium, provided the original work is properly cited.

Antimicrobial materials have attracted much attention all over the world. Herein, a new kind of antimicrobial material, poly (ether amide) $\left(\right.$ Pebax $^{\circledR}$ ) nanofibers containing Ag nanoparticles, was prepared by electrospinning method. The Ag/Pebax ${ }^{\circledR}$ composites were characterized by scanning electron microscopy (SEM), transmission electron microscopy (TEM), X-ray diffraction (XRD), X-ray photoelectron spectroscopy (XPS), differential scanning calorimetry (DSC), and thermogravimetric analyzer (TGA) measurements. The antimicrobial properties of Ag/Pebax ${ }^{\circledR}$ composites against Escherichia coli (E. coli; ATCC25922 and avirulent) and Staphylococcus aureus (S. aureus; ATCC6538 and avirulent) were evaluated by membrane adhering method. It was found that the $\mathrm{Ag}$ content played an important part in the antimicrobial ability of $\mathrm{Ag} / \mathrm{Pebax}{ }^{\circledR}$ composites. When the mass ratio of $\mathrm{AgNO}_{3}$ to Pebax ${ }^{\circledR}$ in the precursor was $0.15 \%$, the inhibition rate can reach $>99.9 \%$ and antimicrobial activity against $E$. coli and S. aureus was 5.8 and 5.6, respectively, exceeding the antimicrobial testing standards JIS Z 2801. The above results indicated that the Ag/Pebax ${ }^{\circledR}$ composite was a promising antimicrobial material that can be used in many applications.

\section{Introduction}

Nowadays, human beings are facing a variety of infectious diseases, not only conventional sicknesses (e.g., malaria) but also emerging viral influenza (such as SARS and avian $f l u$ ), all of which were spread by microorganism. Therefore, in the past few years, antimicrobial agents have been paid more and more attention, in which silver and its compounds were proved to possess potent antimicrobial efficiency against microorganism $[1,2]$. It is generally believed that the bacterial cell will be killed upon the contact with silver, because the positively charged $\mathrm{Ag}$ cations strongly bind to electron donor groups containing sulphur, oxygen, or nitrogen in the cell membrane and enzymes, resulting in structural and functional changes in the cell and finally death of the microorganism [3-7]. Moreover, multiplication of bacteria may be prevented owing to the interaction between the $\mathrm{Ag}^{+}$ and DNA structure $[4,5]$. In addition, because of immediate death of microorganisms upon contact with $\mathrm{Ag}^{+}$, there are minimal chances for development of bacterial resistance [8]. In comparison with $\mathrm{Ag}$ ions, $\mathrm{Ag}$ nanoparticles are superior in heat resistance, chemical stability, release rate of $\mathrm{Ag}^{+}$, and service time, bringing about more opportunities for antimicrobial applications [9].

On the basis of the aforementioned advantages, combining $\mathrm{Ag}$ nanoparticles with polymers to form $\mathrm{Ag} /$ polymer composites has attracted much interest of many researchers, because the $\mathrm{Ag} /$ polymer composite can be applied in diverse fields, such as medical use, daily necessities, and clothing. Recently, Ag/polymers composites with different polymer matrixes, for example, cellulose acetate [10], polyurethane [8], poly (ethylene oxide) [11], poly (vinyl alcohol) [1], and poly (lactic-co-glycolic acid) [12], have been fabricated by electrospinning. The electrospinning is a popular technique 


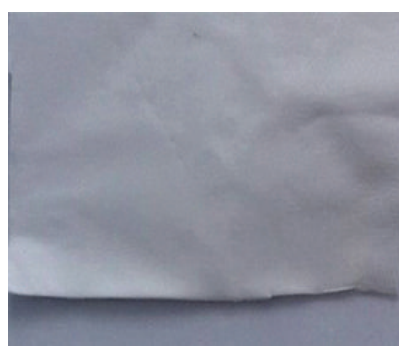

(a)

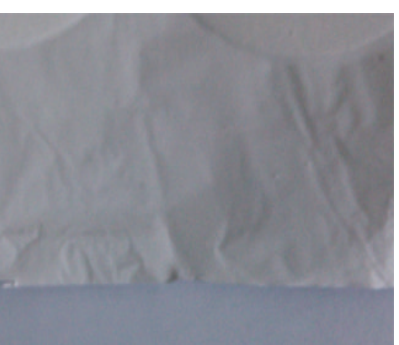

(b)

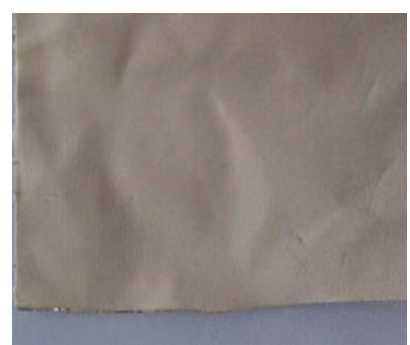

(c)

Figure 1: Optical photographs of an electrospun nanofiber web: (a) Pebax, (b) AgNO 3 /Pebax-3, and (c) Ag/Pebax-3.

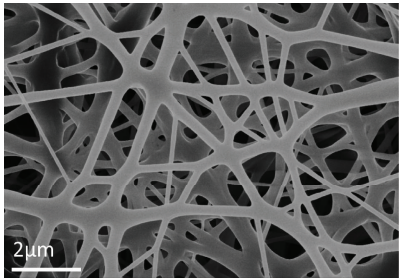

(a)

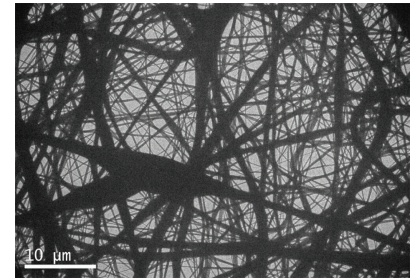

(b)

FIgURE 2: (a) SEM and (b) TEM images of Pebax nanofibers.

to prepare high-performance polymer products due to its cost effectiveness, versatility, and simplicity. Briefly, electrospinning is a process by which a polymer solution is ejected under high electric fields to produce polymeric fibers [13]. The fibers are collected as a nonwoven and porous web with a high surface to volume ratio, small pore sizes, and high porosity $[1,8,14]$, which is suitable for biomedical use, disinfection, water purifying systems, and so on.

Pebax is a kind of copolymer, and its structure unit consists of dodecyl amide and ether components, which offers a perfect combination of mechanical strength, breathability, water barrier property, gas barrier property, flexibility, chemical resistance, no skin allergy, and ease of processing. So it can be used to make urinary catheter, arterial catheter, PTCA (percutaneous transluminal coronary angioplasty) catheter device, infusion bags, and so forth [15-18]. Furthermore, Pebax is a high-performance thermoplastic polyamide elastomer with excellent durability and workability, which can be widely used as high-performance sports materials [1921]. If the antibacterial ability can be rendered to the Pebax by embedding Ag nanoparticles, the performance of Pebax will be dramatically improved with certainty. However, to the best of our knowledge, the preparation of Ag/Pebax composite has not been reported so far.

Herein, we employed electrospinning technique and ultraviolet treatment to prepare Ag/Pebax composites without any other reducing agent. The size-uniform Ag nanoparticles were well dispersed in the Pebax matrix. The antimicrobial properties of this Ag/Pebax composite against Escherichia coli and Staphylococcus aureus were studied via membrane adhering method. Study results showed that Ag/Pebax presented excellent antimicrobial properties at an ultralow $\mathrm{AgNO}_{3}$ content in the precursor $(0.15 \%$ ), which was much lower than that of conventional antimicrobial Ag/polymer composites reported in the literature $[1,8-10,12]$, making Ag/Pebax composite a promising antimicrobial material with low-cost and excellent antimicrobial properties, which could be widely used in many fields in the near future.

\section{Experimental Section}

2.1. Preparation of Ag/Pebax Composites. First, Pebax 2533 (ARKEMA Firm) was added into isopropanol (Shanghai Lingfeng, >99\%) and the mixture was magnetically stirred for $5 \mathrm{~h}$ at $60^{\circ} \mathrm{C}$ to obtain Pebax solution with a concentration of $66.7 \mathrm{mg} \mathrm{mL}^{-1}$. Meanwhile, $6.7 \mathrm{mg} \mathrm{mL}^{-1} \mathrm{AgNO}_{3}$ (Shanghai Lingfeng, 99.99\%) in isopropanol solution was prepared in dark. Then a given amount of $\mathrm{AgNO}_{3}$ solution was added into the Pebax solution and the mass ratio of $\mathrm{AgNO}_{3}$ to Pebax was controlled from $0.05 \%$ o to $0.25 \%$. After sonication, the homogeneous solution was fed into a positively charged spinneret with a diameter of $0.6 \mathrm{~mm}$ attached to an electrospinning apparatus [22]. The voltage used for electrospinning was $13 \mathrm{kV}$ and the collection distance was $10 \mathrm{~cm}$. The solution was spun under its own gravity without flow control equipment and the product obtained $\left(\mathrm{AgNO}_{3} /\right.$ Pebax $)$ was dried freely in air. Finally, the as-prepared samples were treated under UV light $(254 \mathrm{~nm}, 14 \mathrm{~W})$ for $6 \mathrm{~h}$ to obtain $\mathrm{Ag} /$ Pebax composites, which was denoted as Ag/Pebax-1, Ag/Pebax-2, Ag/Pebax-3, $\mathrm{Ag} /$ Pebax-4, and Ag/Pebax-5 for the sample with the mass ratio of $\mathrm{AgNO}_{3}$ to Pebax at $0.05 \%$ o, $0.10 \%$, 0.15\%o, 0.20\%o, and $0.25 \%$, respectively. 


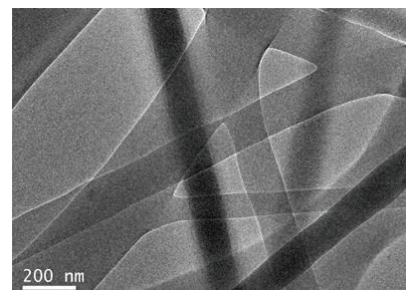

(a)
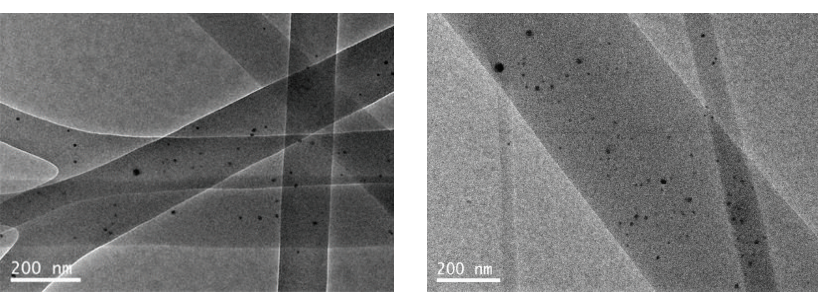

(b)
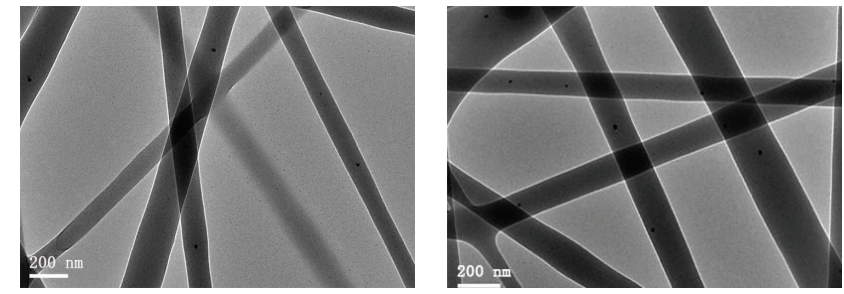

(c)

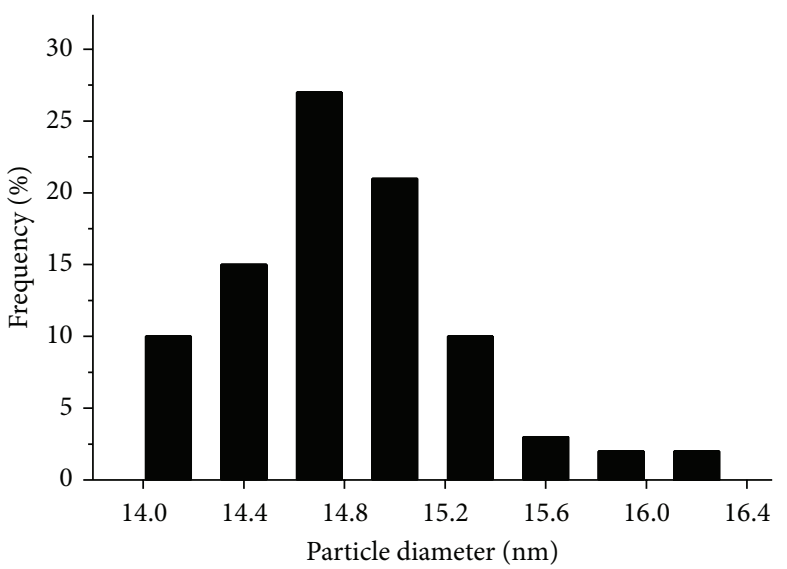

(e)

(f)

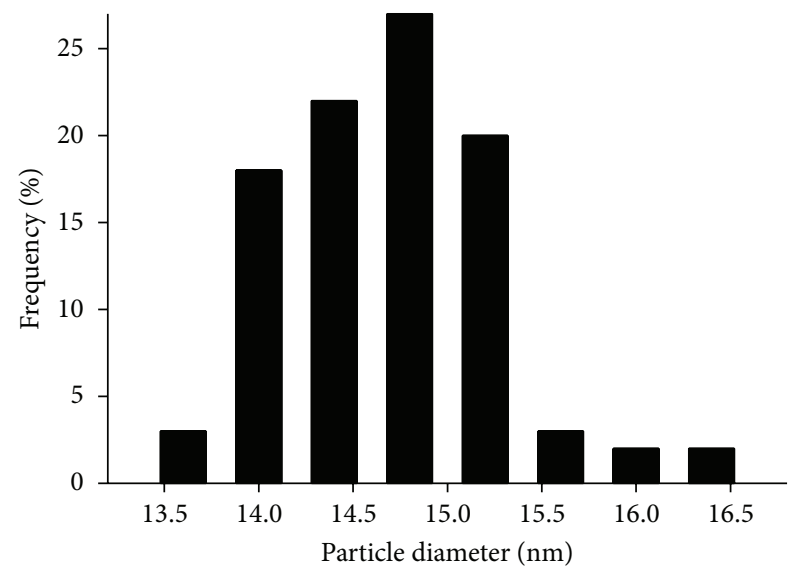

(h)

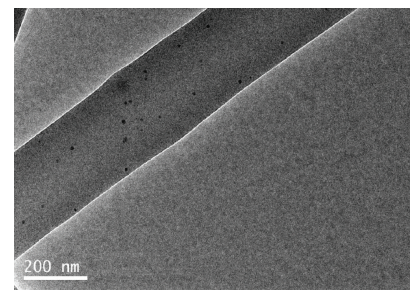

(d) (g)

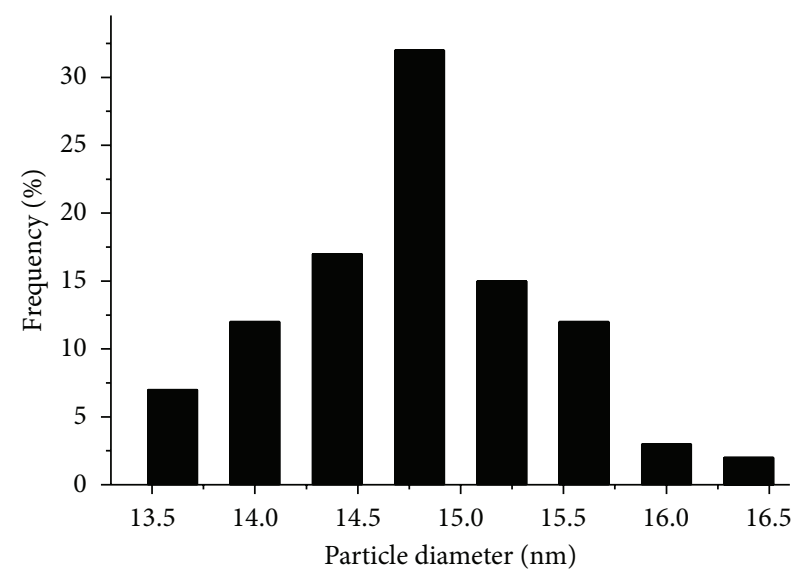

(i)

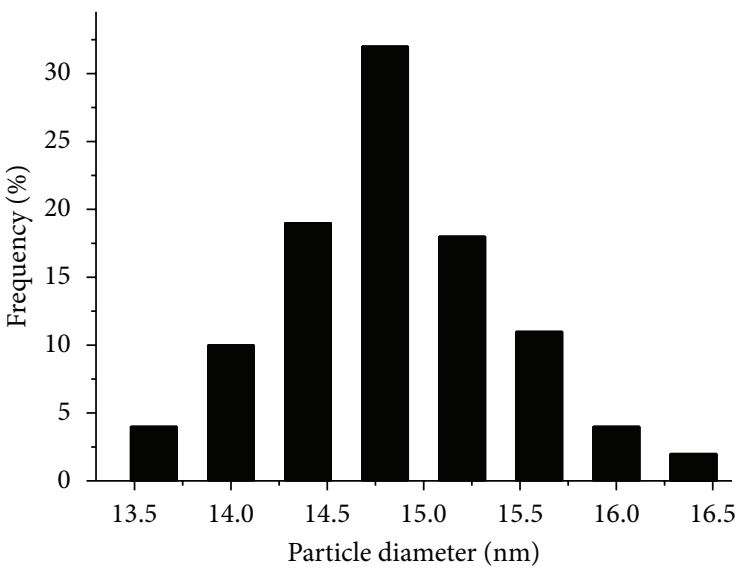

(j)

Figure 3: Continued. 


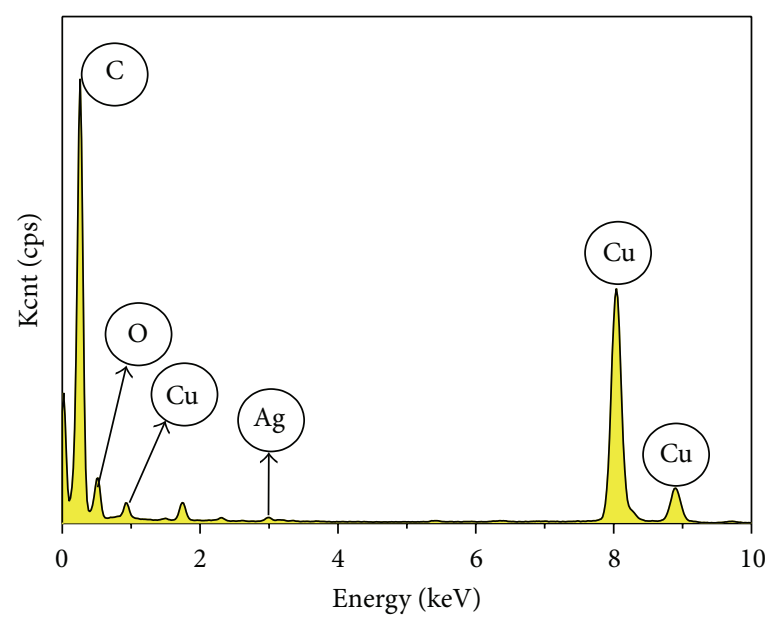

(k)

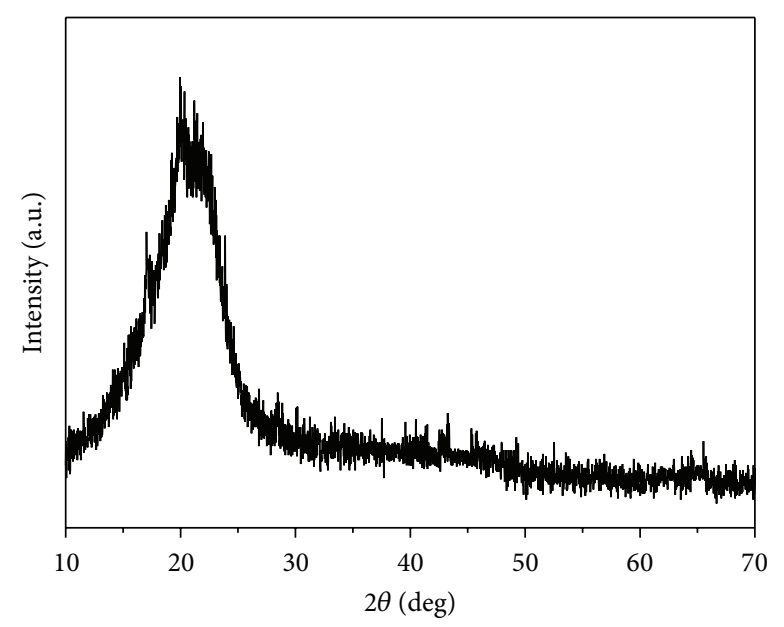

(1)

Figure 3: ((a)-(f)) TEM images of (a) Pebax, (b) Ag/Pebax-1, (c) Ag/Pebax-2, (d) Ag/Pebax-3, (e) Ag/Pebax-4, and (f) Ag/Pebax-5. ((g)(j)) The particle size distribution of Ag nanoparticles of (g) Ag/Pebax-2, (h) Ag/Pebax-3, (i) Ag/Pebax-4, and (j) Ag/Pebax-5. (k) The EDS spectrum of Ag/Pebax-5. (1) The XRD patterns of Ag/Pebax-5.

2.2. Characterizations. The morphology of the resulting electrospun nonwoven fiber mat was evaluated using scanning electron microscopy (SEM, Zeiss, SUPRA 55, Germany). The transmission electron microscopy (TEM) image was obtained on a JEOL JEM-2100 microscope operating at $200 \mathrm{kV}$ equipped with energy dispersive spectrometer (EDS). The crystalline structure of the sample was identified by Xray diffraction (XRD, Rigaku D/max 2500PC) using $\mathrm{Cu} \mathrm{K} \alpha$ radiation. A simultaneous differential scanning calorimeter (PerkinElmer, DSC 8500, USA) was operated in the temperature range from $-40^{\circ} \mathrm{C}$ to $80^{\circ} \mathrm{C}$ with a heating rate of $10^{\circ} \mathrm{C} \mathrm{m^{-1 }}$ under a nitrogen atmosphere. The thermal degradation behaviors of Ag/Pebax nanofibers were studied on a thermogravimetric analyzer (PerkinElmer, Pyris 1 TGA, USA) from $30^{\circ} \mathrm{C}$ to $800^{\circ} \mathrm{C}$ at a heating rate of $10^{\circ} \mathrm{C} \mathrm{min} \mathrm{m}^{-1}$ under nitrogen at a flow rate of $20 \mathrm{~mL} \mathrm{~min}^{-1}$. The chemical state of the sample was examined by X-ray photoelectron spectroscopy (XPS) on a VG Scientific ESCALABMKLL spectrometer using $\mathrm{Al} \mathrm{K} \alpha \mathrm{X}$-ray source $(10 \mathrm{~mA}, 15 \mathrm{kV})$.

\subsection{Bacterial Culture and Test for Antibacterial Activity.}

The bacteria used for the test were Escherichia coli (E. coli: ATCC25922) and Staphylococcus aureus (S. aureus: ATCC6538). Any water used was distilled and all reagents were of a grade appropriate for microbiological purposes. The stock culture was stored at $5^{\circ} \mathrm{C}$ to $10^{\circ} \mathrm{C}$ on an appropriate medium and the bacteria were transferred from the stock culture to a slant culture medium and incubated at $(35 \pm 1)^{\circ} \mathrm{C}$ for $24 \mathrm{~h}$. Then bacteria were transferred onto another slant culture medium and incubated for another $20 \mathrm{~h}$. After that, the bacteria were transferred into $1 / 500 \mathrm{NB}$ (nutrient broth) prepared in advance, obtaining a bacterial concentration between $2.5 \times 10^{5}$ and $10 \times 10^{5}$ cells $\mathrm{mL}^{-1}$, which was used as the test inoculum. Then $0.4 \mathrm{~mL}$ of the test inoculum was pipetted onto the test surface and covered by a piece of square Ag/Pebax film with side length of $40 \mathrm{~mm}$ and a thickness of $\sim 1 \mathrm{~mm}$. The test specimen was incubated at $(35 \pm 1)^{\circ} \mathrm{C}$ with a relative humidity of $90 \%$ for $24 \mathrm{~h}$. After incubation, $20 \mathrm{~mL}$ of neutralizer was added to wash the specimen and then the viable bacteria count was determined by pour-plate culture method. For the testing, all petri dishes should be inverted and incubated at $(35 \pm 1)^{\circ} \mathrm{C}$ for $40 \mathrm{~h}$, and then the number of colonies in petri dishes was counted [22].

The number of viable bacteria was calculated by

$$
N=C \times D \times V
$$

where $N$ is the number of viable bacteria recovered per test specimen; $C$ is the average plate count for the duplicate plates; $D$ is the dilution factor for the plate counted; and $V$ is the volume in $\mathrm{mL}$ of neutralizer added to the specimen.

The antibacterial activity was calculated by

$$
R=U_{t}-A_{t}
$$

where $R$ is the antibacterial activity; $U_{t}$ is the average of the common logarithm of the number of viable bacteria recovered from the untreated test specimens after $24 \mathrm{~h}$; and $A_{t}$ is the average of the common logarithm of the number of viable bacteria recovered from the treated specimens after $24 \mathrm{~h}[23,24]$.

\section{Results and Discussion}

The electrospun Pebax was tough and flexible, and it is white in color (Figure 1(a)). The SEM and TEM images (Figure 2) indicated that the electrospun Pebax was mesh on a microlevel formed by the connection between Pebax nanofibers, proving that the electrospinning technique can be applied successfully on Pebax.

In order to confer antibacterial ability to Pebax, $\mathrm{AgNO}_{3}$ was electrospun with Pebax simultaneously and the asprepared samples were treated with UV light to decompose $\mathrm{AgNO}_{3}$ to metallic Ag. As shown in Figure 1(c), 


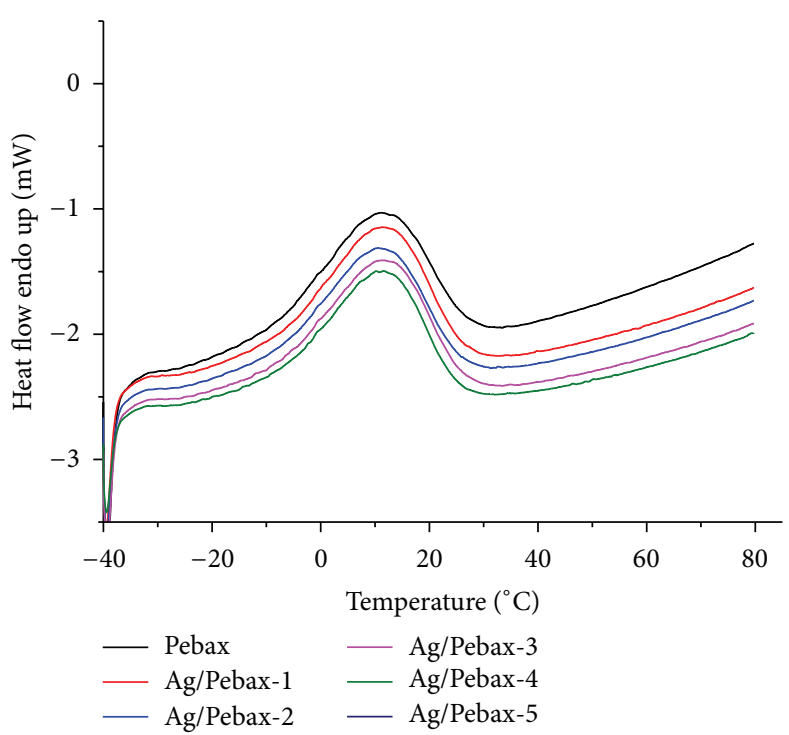

(a)

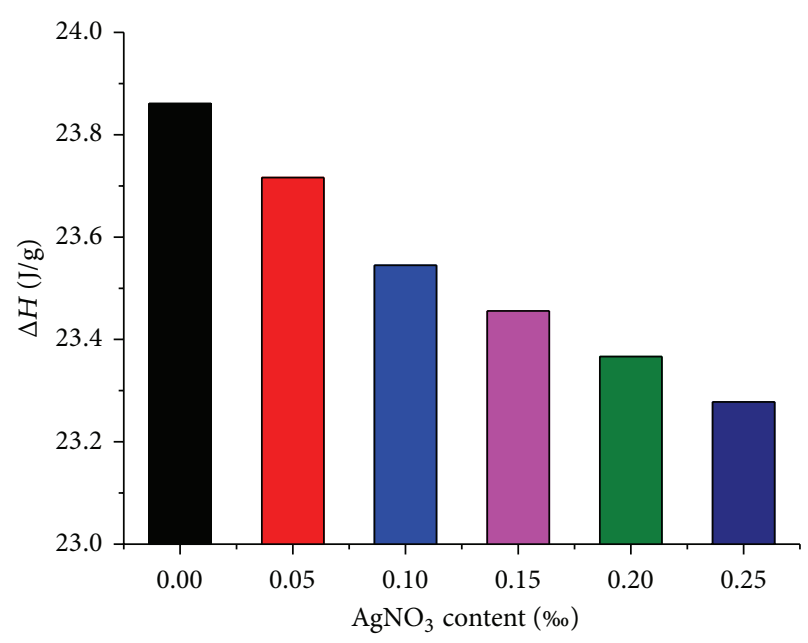

(b)

Figure 4: (a) DSC diagrams and (b) the heat of fusion for pure Pebax nanofibers and Ag/Pebax composites with different $\mathrm{AgNO}_{3}$ contents.

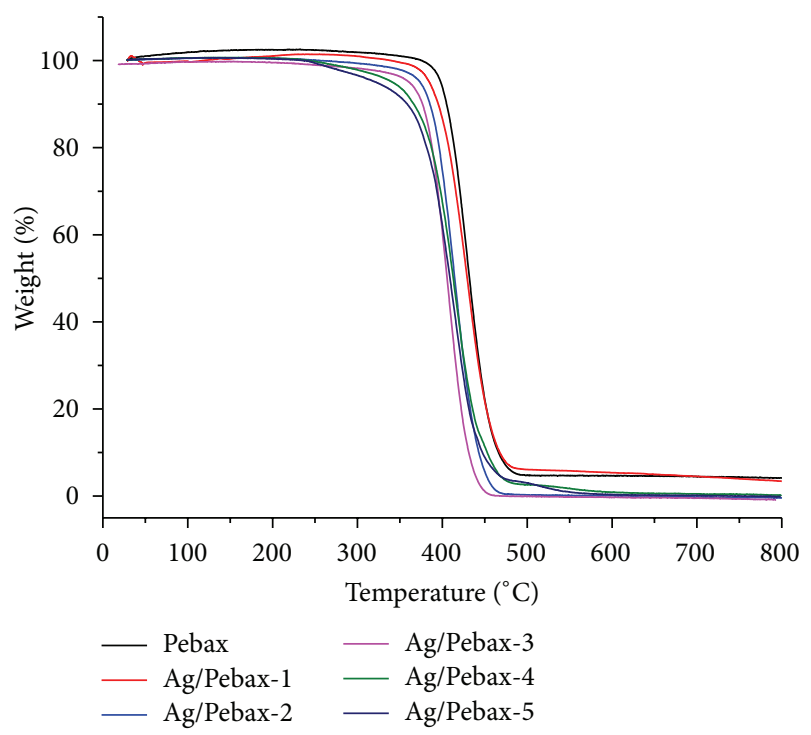

Figure 5: TGA data of pure Pebax nanofibers and Ag/Pebax composite with different $\mathrm{AgNO}_{3}$ contents.

the Ag/Pebax composite was pale yellow in color which was obviously different from that of pure Pebax (Figure 1(a)) and $\mathrm{AgNO}_{3} /$ Pebax composite (Figure 1(b)). The color change should come from the presence of metallic Ag in Ag/Pebax composite, so we further studied the composite by TEM. As shown in Figures 3(b)-3(f), the metallic Ag was in near spherical morphology and Ag nanoparticles were dispersed homogeneously within the fiber matrix. Although the number density of Ag nanoparticles in the Pebax matrix was increased with the $\mathrm{AgNO}_{3}$ content, no aggregation was observed. In addition, the Ag particle diameter distribution

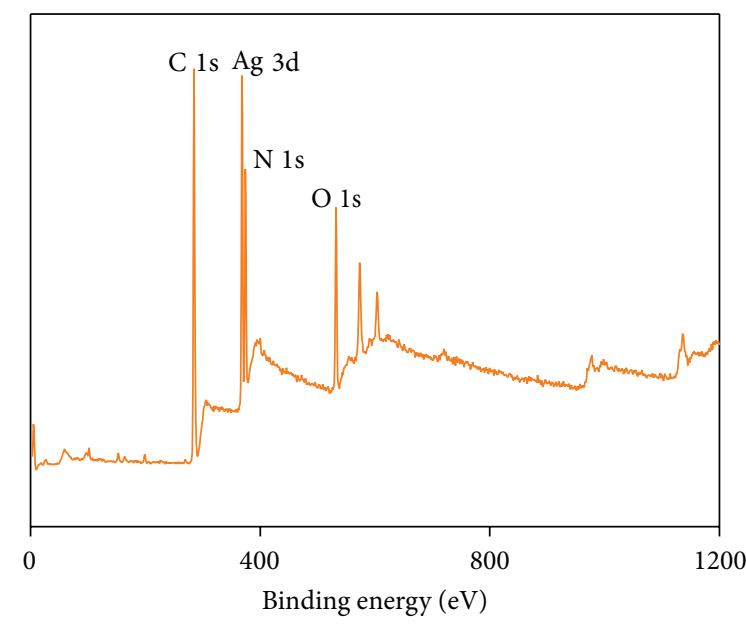

FIgURE 6: XPS spectrum of Ag/Pebax-3.

of Ag/Pebax-2 to Ag/Pebax-5 is shown in Figures 3(g) to 3(j), respectively, which was obtained by measuring about $200 \mathrm{Ag}$ nanoparticles for each sample. Both of the particle diameters of the two samples ranged between $13.5 \mathrm{~nm}$ and $16.5 \mathrm{~nm}$, with average particle size at 14.8, 14.9, 14.7, and $14.8 \mathrm{~nm}$ for Ag/Pebax-2 to Ag/Pebax-5, respectively, on the assumption of Gaussian distribution. Since the density of Ag particle in Ag/Pebax-1 was very low, its average particle size was calculated to be $14.8 \mathrm{~nm}$ by using the arithmetic mean value of all Ag particles. The above results indicated that the mean particle size of Ag nanoparticles nearly did not change with the increase of Ag content, which may be due to the fact that the $\mathrm{Ag}$ content was very low and $\mathrm{AgNO}_{3}$ was completely dissolved in the solution; thus the $\mathrm{AgNO}_{3}$ crystals after electrospinning were distributed 


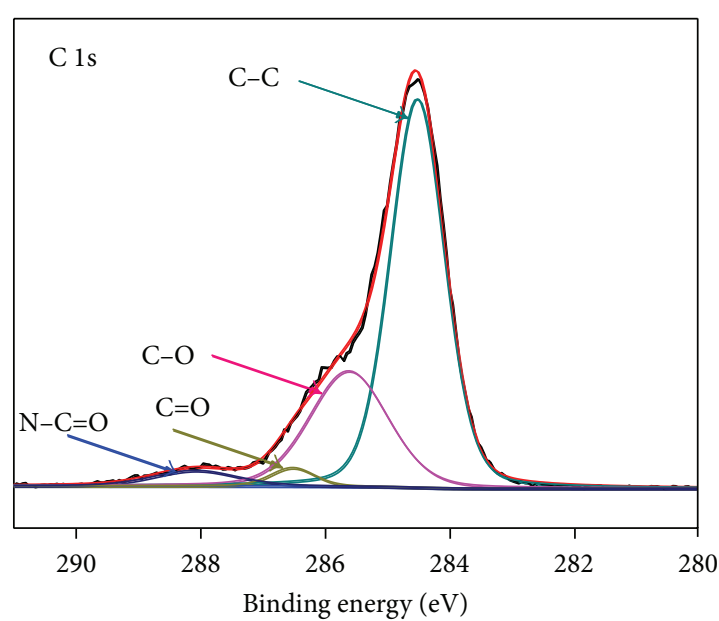

(a)

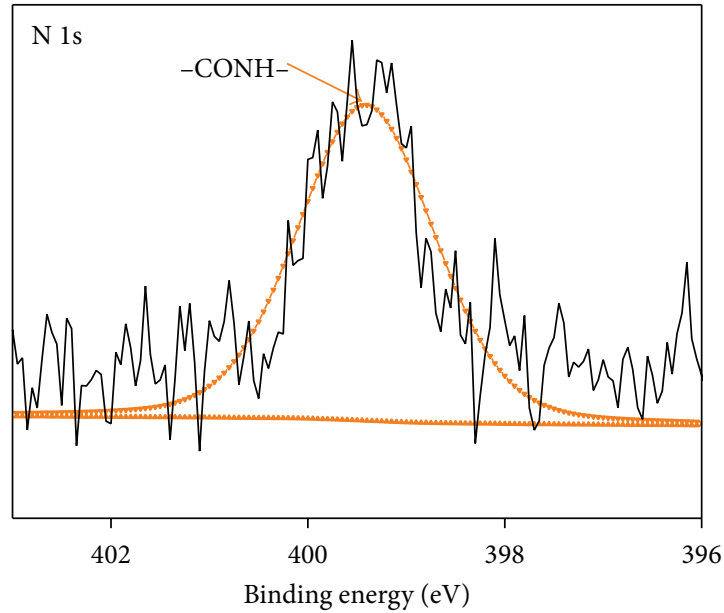

(c)

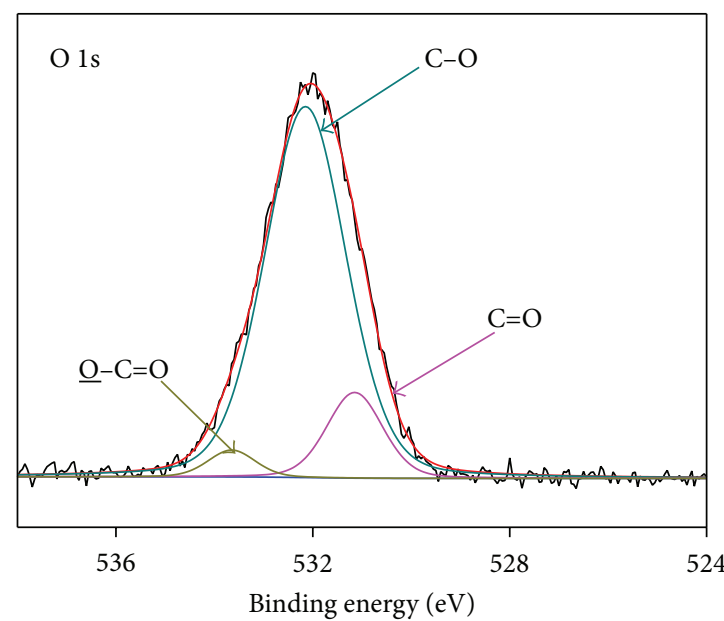

(b)

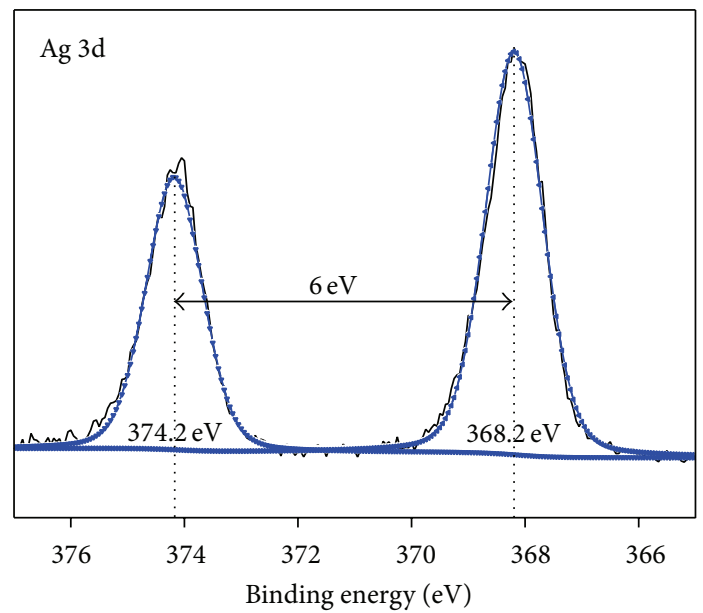

(d)

FIgUre 7: XPS deconvolution spectrum of (a) C 1s, (b) O 1s, (c) N 1s, and (d) Ag 3d core levels of Ag/Pebax-3.

uniformly in the Pebax matrix, resulting in the fact that the $\mathrm{Ag}$ nanoparticles reduced were also monodisperse and the mean particle size only fluctuated slightly at different $\mathrm{Ag}$ loadings. Additionally, the EDS spectrum of Ag/Pebax-5 in Figure $3(\mathrm{k})$ confirmed the ultralow content of $\mathrm{Ag}$ content in the composite. The crystalline information of Ag/Pebax- 5 was analyzed by XRD. As shown in Figure 3(1), the diffraction peak at $20^{\circ}$ was ascribed to pure Pebax 2533 [25]. According to JCPDS 04-0783 (Ag), the crystalline Ag should be revealed by diffraction peaks at $2 \theta$ values of $38.12^{\circ}, 44.28^{\circ}$, and $64.43^{\circ}$. However, no distinctive diffraction of silver was observed in the Ag/Pebax composite even for Ag/Pebax-5 with the highest concentration of $\mathrm{AgNO}_{3}(0.25 \%$ ) (Figure 3(l)). It was probably because of the fact that the concentration of $\mathrm{Ag}$ included in the composite was below the detection limit of the XRD method [26].

To investigate the effect of silver on the crystallinity of Pebax, we performed DSC measurements in a $\mathrm{N}_{2}$ atmosphere. Formula for calculating the degree of crystallization $\left(X_{c}\right)$ was $X_{c}=\Delta H / \Delta H_{o}$, where $\Delta H$ is the heat of fusion of the sample in this experiment and $\Delta H_{o}$ is the heat of fusion of pure Pebax with $100 \%$ crystallinity which is a constant here. Figure 4(a) shows the DSC thermograms for Pebax and the $\mathrm{Ag} / \mathrm{Pebax}$ composite between $-40^{\circ} \mathrm{C}$ and $80^{\circ} \mathrm{C}$. It was found that the $\Delta H$ of $\mathrm{Ag} / \mathrm{Pebax}$ composites was lower than that of pure Pebax, indicating that the $X_{c}$ of Pebax polymer was reduced in the presence of $\mathrm{Ag}$ nanoparticles. Furthermore, the reduction in crystallinity was enhanced with the increase of the $\mathrm{AgNO}_{3}$ content (Figure 4(b)). In addition, the glass transition temperature $\left(T_{q}\right)$ for Pebax, Ag/Pebax1, Ag/Pebax-2, Ag/Pebax-3, Ag/Pebax-4, Ag/Pebax-5, and Ag/Pebax- 6 is $-6.80^{\circ} \mathrm{C},-7.34^{\circ} \mathrm{C},-7.52^{\circ} \mathrm{C},-7.95^{\circ} \mathrm{C},-8.13^{\circ} \mathrm{C}$, $-8.25^{\circ} \mathrm{C}$, and $-8.36^{\circ} \mathrm{C}$, respectively, indicating that the $T_{g}$ of Pebax polymer is gradually reduced with the increase of the $\mathrm{AgNO}_{3}$ content. Generally, the regular structure of ether segments is in favor of the crystallization [27]. In this work, with the increase of Ag content, the regularity of the internal structure of Pebax was reduced, whereas the flexibility of the polymer chain was improved [28], which may result in the decrease of the $X_{c}$ and $T_{g}$.

The thermal degradation behaviors of Ag/Pebax nanofibers were studied with a TGA under nitrogen atmosphere. 


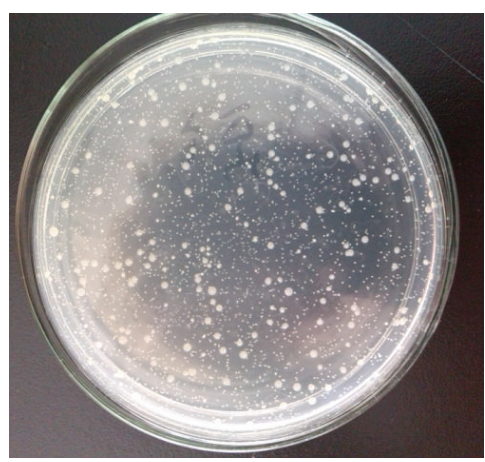

(a)

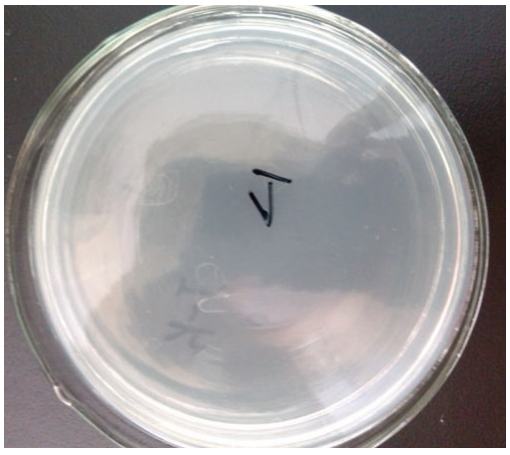

(d)

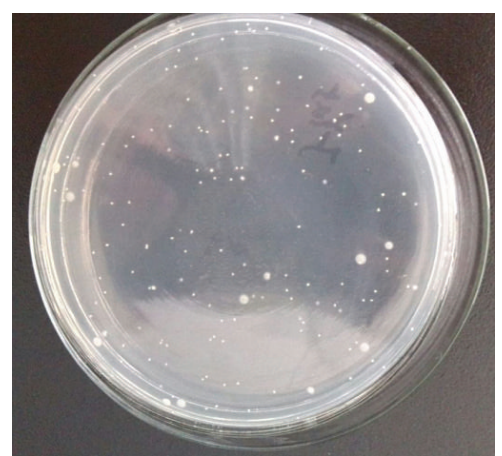

(b)

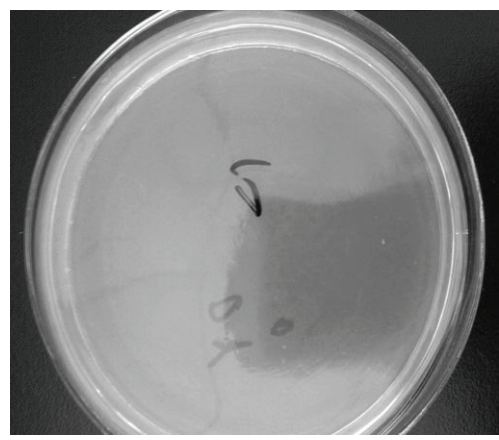

(e)

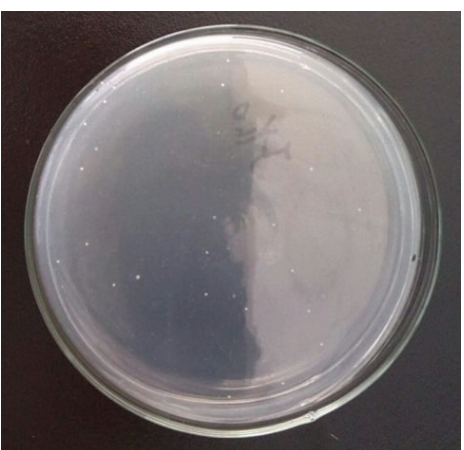

(c)

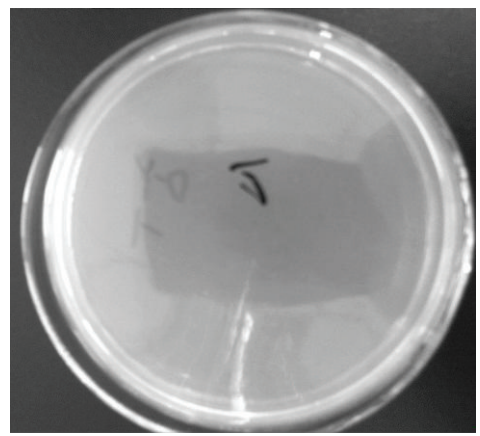

(f)

Figure 8: Comparison of the antibacterial ability of (a) Pebax, (b) Ag/Pebax-1, (c) Ag/Pebax-2, (d) Ag/Pebax-3, (e) Ag/Pebax-4, and (f) Ag/Pebax-5 against E. coli.

With the increase of $\mathrm{Ag}$ content, the onset decomposition temperature of the $\mathrm{Ag} / \mathrm{Pebax}$ composite gradually decreased. As shown in Figure 5, the onset decomposition temperature of Pebax, Ag/Pebax-1, Ag/Pebax-2, Ag/Pebax-3, Ag/Pebax4, and $\mathrm{Ag} /$ Pebax -5 is $350.14^{\circ} \mathrm{C}, 330.62^{\circ} \mathrm{C}, 310.77^{\circ} \mathrm{C}, 291.30^{\circ} \mathrm{C}$, $273.10^{\circ} \mathrm{C}$, and $250.21^{\circ} \mathrm{C}$, respectively. Because the $\mathrm{Ag}$ nanoparticles dispersed uniformly in the nanofibers and their particle size nearly did not change at different Ag contents, the increase of Ag content in nanofibers will increase the number of $\mathrm{Ag}$ nanoparticles, which can weaken the tightness of the Pebax molecule arrangement and expand the volume of noncrystalline region in the nanofiber, resulting in the decrease of thermal stability of the whole composite, that is, a drop of the onset decomposing temperature. Additionally, Ag nanoparticles may also play a catalytic role in the decomposition during DSC measurement.

The chemical state and near surface composition of the $\mathrm{Ag} / \mathrm{Pebax}$ composite were studied by XPS. With a survey range of $0-1200 \mathrm{eV}$, four elements can be detected: carbon, silver, nitrogen, and oxygen (Figure 6). Figure 7 shows the high-resolution XPS spectra of Ag/Pebax-3. From the analysis of $\mathrm{C}$ 1s spectrum (Figure 7(a)), we can see carbon atoms in the $\mathrm{C}-\mathrm{C}$ bond, $\mathrm{C}-\mathrm{O}$ bond, $\mathrm{C}=\mathrm{O}$ bond, and $\mathrm{N}-\mathrm{C}=\mathrm{O}$ at $284.5 \mathrm{eV}, 285.6 \mathrm{eV}, 286.5 \mathrm{eV}$, and $288.1 \mathrm{eV}$, respectively. The peak at $532.1 \mathrm{eV}$ in the $\mathrm{O}$ 1s spectrum (Figure 7(b)) is attributed to the oxygen in the $\mathrm{C}-\mathrm{O}$ bond and the peaks at
$531.1 \mathrm{eV}$ and $533.7 \mathrm{eV}$ are assigned to the oxygen of $\mathrm{C}=\mathrm{O}$ and $\mathrm{O}-\mathrm{C}=\mathrm{O}$ bonds, respectively [29]. The $\mathrm{N} 1 \mathrm{~s}$ spectrum presents a peak at $399.4 \mathrm{eV}$ which comes from the nitrogen in the - CONH- group. In the XPS spectrum of Ag 3d (Figure 7(d)), two peaks were observed at 368.2 and $374.2 \mathrm{eV}$, which can be ascribed to $\mathrm{Ag}\left(3 \mathrm{~d}_{5 / 2}\right)$ and $\mathrm{Ag}\left(3 \mathrm{~d}_{3 / 2}\right)$ peaks, respectively. Moreover, the splitting of the $3 \mathrm{~d}$ doublet of $\mathrm{Ag}$ was $6.0 \mathrm{eV}$, which indicates that these $\mathrm{Ag} / \mathrm{Pebax}$ composites only contain metallic $\mathrm{Ag}\left(\mathrm{Ag}^{0}\right)$ [30-32], indicating the complete reduction of $\mathrm{AgNO}_{3}$ by UV.

The potential use of Ag/Pebax composite as antibacterial material was assessed by observing their antibacterial activity against two kinds of common bacteria, E. coli and S. aureus. The electrospun Pebax without Ag was evaluated in a control experiment. The bacteria were incubated in a growth medium containing various nanofibers and the antibacterial properties of samples were tested by membrane adhering method, following the antibacterial testing standard (JISZ 2801:2010). The changes in the content of Ag had a significant effect on the antibacterial properties of Ag/Pebax composite. The number density of bacterial colony for pure Pebax was high (Figure $8(\mathrm{a})$ ), and both of the antibacterial rate (1) and antimicrobial activity (2) were nearly zero (Figure 9); that is, there was no antibacterial activity observed for Agfree pure Pebax. In contrast, the samples added with small amount of $\mathrm{AgNO}_{3}$ in the Pebax precursor solution showed 


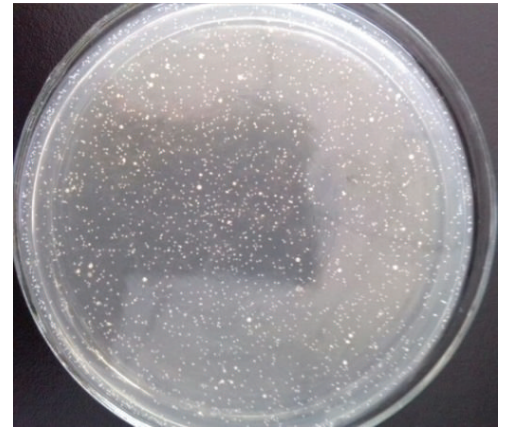

(a)

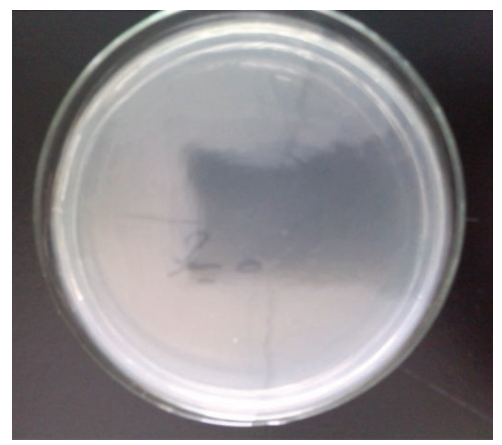

(d)

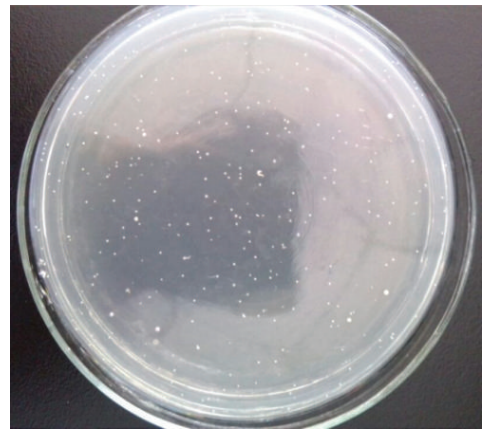

(b)

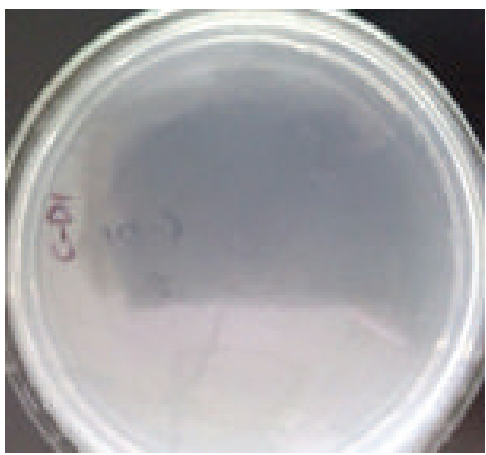

(e)

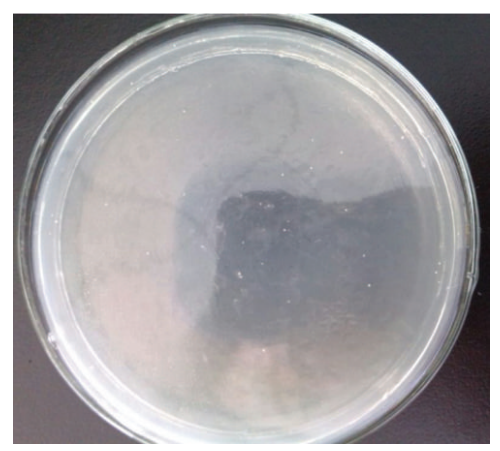

(c)

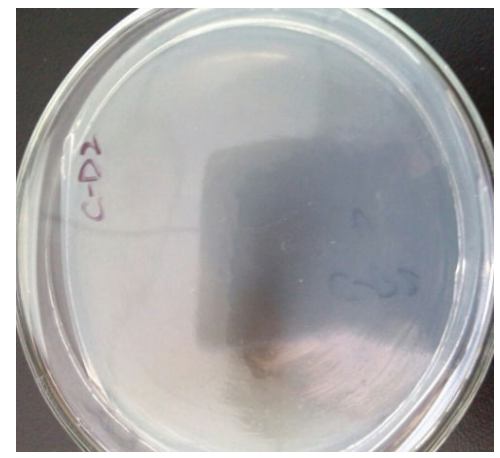

(f)

Figure 9: Comparison of the antibacterial ability of (a) Pebax, (b) Ag/Pebax-1, (c) Ag/Pebax-2, (d) Ag/Pebax-3, (e) Ag/Pebax-5, and (f) Ag/Pebax-6 against $S$. aureus.

an inhibitory effect on $E$. coli and S. aureus. Although the content of $\mathrm{AgNO}_{3}$ was only $0.05 \%$ (Figures 8(b) and 9(b)), the antibacterial rate against $E$. coli and $S$. aureus can reach $88.2 \%$ and $76.1 \%$, respectively. Furthermore, the antibacterial properties of Ag/Pebax composite were enhanced gradually with the increase of $\mathrm{AgNO}_{3}$ concentration (Figures 8(b)8(d), 9(b)-9(d) and 10). When the $\mathrm{AgNO}_{3}$ content reached $0.15 \%$, no bacterial colony can be observed (Figures $8(\mathrm{~d})$ and 9(d)) and the inhibition rates all larger than 99.9\%, and the value of antimicrobial activity against $E$. coli and $S$. aureus was 5.8 and 5.6, respectively (Figure 10). Further increasing the content of $\mathrm{Ag}$ failed to enhance the antibacterial properties of Ag/Pebax any more (Figures 8(e)-8(f), 9(e)-9(f) and 10). Because the Pebax did not show antibacterial ability, Ag nanoparticles were responsible for the antibacterial ability of $\mathrm{Ag} /$ Pebax composites. It was reported that the antimicrobial property of material containing silver is mainly determined by the total release rate of silver ions [32]. In this work, owing to the stable particle size, the increase of Ag content will lead to the enlargement of the number and the total surface area of Ag nanoparticles; thus the release rate of silver ions was accelerated, giving rise to the improvement of antibacterial ability of Ag/Pebax composites (Figure 10). According to the antimicrobial testing standard JISZ 2801:2010, the sample whose antimicrobial activity is greater than $2(R>2)$ passes the antibacterial test of the strain $(R>2$ means the antibacterial efficiency can reach $99 \%$ or more). According to the experimental results, it can be concluded that the $\mathrm{Ag} /$ Pebax composite with $\mathrm{AgNO}_{3}$ content larger than $0.15 \%$ presented excellent antibacterial properties, and this $\mathrm{Ag}$ content was much lower than that of Ag/polymer composites reported in the literature (usually larger than $1 \mathrm{wt} . \%)[1,7$, 8, 11, 33-35], making Ag/Pebax a promising antibacterial material with potential application in a number of fields, such as biomedical materials, sports apparatus, and laminating films.

\section{Conclusions}

This study has described a simple route to prepare welldispersed and size-uniform Ag nanoparticles in Pebax nanofibers via an electrospinning process. Ag nanoparticles with an average diameter of ca. $15 \mathrm{~nm}$ were dispersed homogeneously in Pebax nanofibers. The antimicrobial activities of Ag/Pebax composite against E. coli and S. aureus were evaluated by membrane adhering method. Study results indicated that the Ag/Pebax composites presented outstanding antimicrobial properties at ultralow Ag content; for example, the inhibition rate can reach $>99.9 \%$ and antimicrobial activity against $E$. coli and $S$. aureus was 5.8 and 5.6 at the critical value of $\mathrm{AgNO}_{3}$ content (0.15\%o), respectively, which suggested that the Ag/Pebax composite can be used as a promising antimicrobial material. 


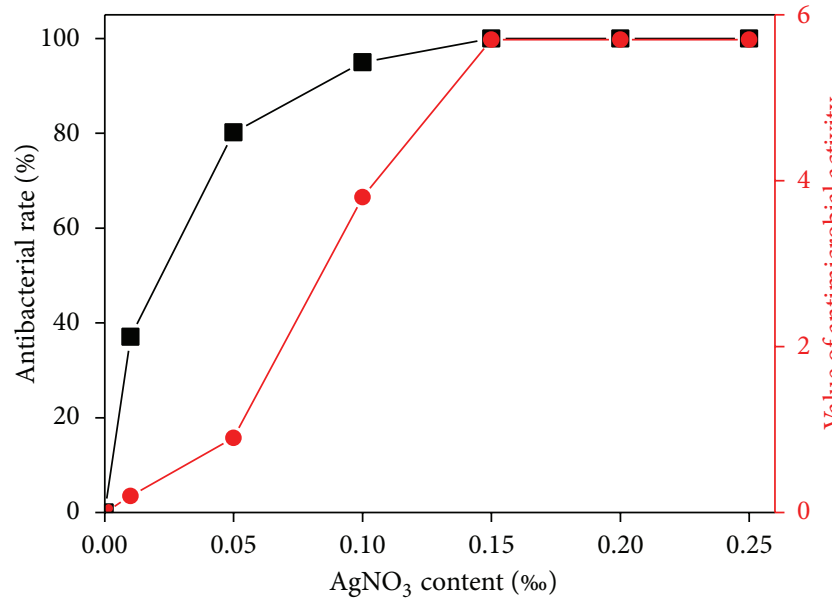

(a)

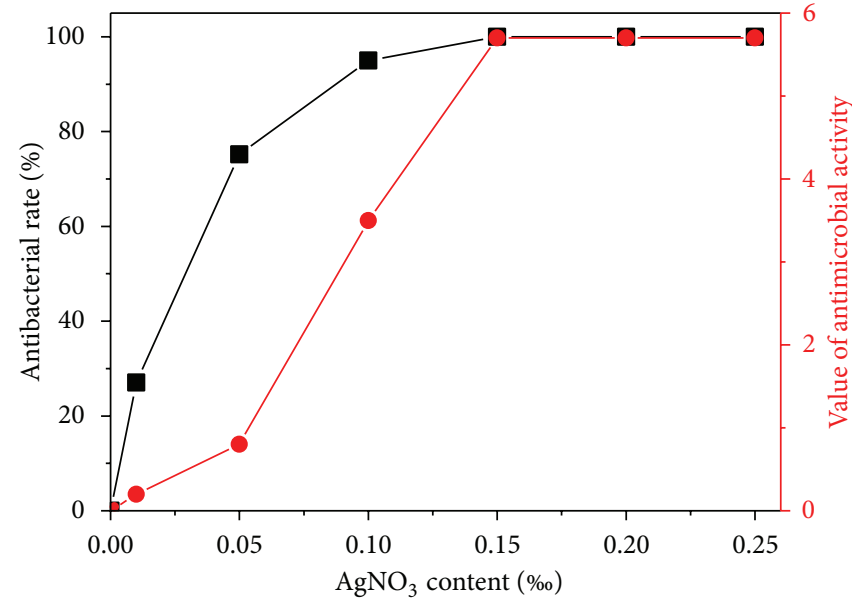

(b)

Figure 10: The antibacterial rate and antimicrobial activity of $\mathrm{Ag} / \mathrm{Pebax}$ against E. coli and S. aureus as a function of $\mathrm{AgNO}_{3}$ content in the precursor.

\section{Conflict of Interests}

The authors declare that they have no financial and personal relationships with other people or organizations that can inappropriately influence their work; there is no professional or other personal interest of any nature or kind in any product, service, and/or company that could be construed as influencing the position presented in, or the review of, the paper entitled.

\section{Acknowledgments}

This work was financially supported by the National Natural Science Foundation of China under Grant (no. 21373034); the Specially Hired Professorship-Funding of Jiangsu province under Grant (no. SCZ1211400001); the start-up funds from Changzhou University Jiangsu province; Jiangsu Key Laboratory of Advanced Catalytic Material and Technology; and Key Laboratory of Fine Petrochemical Engineering and PAPD of Jiangsu Higher Education Institutions. This trademark belongs to Arkema France and is related to polyether block amides.

\section{References}

[1] M. S. Islam and J. H. Yeum, "Electrospun pullulan/poly(vinyl alcohol)/silver hybrid nanofibers: preparation and property characterization for antibacterial activity," Colloids and Surfaces A: Physicochemical and Engineering Aspects, vol. 436, no. 5, pp. 279-286, 2013.

[2] G. Jin, M. P. Prabhakaran, B. P. Nadappuram, G. Singh, D. Kai, and S. Ramakrishna, "Electrospun poly(L-lactic acid)-copoly ( $\epsilon$-caprolactone) nanofibres containing silver nanoparticles for skin-tissue engineering," Journal of Biomaterials Science, Polymer Edition, vol. 23, no. 18, pp. 2337-2352, 2012.

[3] T. Hamouda, A. Myc, B. Donovan, A. Y. Shih, J. D. Reuter, and J. R. Baker Jr., "A novel surfactant nanoemulsion with a unique non-irritant topical antimicrobial activity against bacteria, enveloped viruses and fungi," Microbiological Research, vol. 156, no. 1, pp. 1-7, 2001.

[4] T. Yuranova, A. G. Rincon, A. Bozzi et al., "Antibacterial textiles prepared by RF-plasma and vacuum-UV mediated deposition of silver," Journal of Photochemistry and Photobiology A: Chemistry, vol. 161, no. 1, pp. 27-34, 2003.

[5] Q. L. Feng, J. Wu, G. Q. Chen, F. Z. Cui, T. N. Kim, and J. O. Kim, "A mechanistic study of the antibacterial effect of silver ions on Escherichia coli and Staphylococcus aureus," Journal of Biomedical Materials Research, vol. 52, no. 4, pp. 662-668, 2000.

[6] I. Sondi and B. Salopek-Sondi, "Silver nanoparticles as antimicrobial agent: a case study on E. coli as a model for Gramnegative bacteria," Journal of Colloid and Interface Science, vol. 275, no. 1, pp. 177-182, 2004.

[7] Y. Matsumura, K. Yoshikata, S. Kunisaki, and T. Tsuchido, "Mode of bactericidal action of silver zeolite and its comparison with that of silver nitrate," Applied and Environmental Microbiology, vol. 69, no. 7, pp. 4278-4281, 2003.

[8] F. A. Sheikh, N. A. M. Barakat, M. A. Kanjwal et al., "Electrospun antimicrobial polyurethane nanofibers containing silver nanoparticles for biotechnological applications," Macromolecular Research, vol. 17, no. 9, pp. 688-696, 2009.

[9] H. H. Chae, B. Kim, K. S. Yang, and J. I. Rhee, "Synthesis and antibacterial performance of size-tunable silver nanoparticles with electrospun nanofiber composites," Synthetic Metals, vol. 161, no. 19-20, pp. 2124-2128, 2011.

[10] W. K. Son, J. H. Youk, and W. H. Park, "Antimicrobial cellulose acetate nanofibers containing silver nanoparticles," Carbohydrate Polymers, vol. 65, no. 4, pp. 430-434, 2006.

[11] C. D. Saquing, J. L. Manasco, and S. A. Khan, "Electrospun nanoparticle-nanofiber composites via a one-step synthesis," Small, vol. 5, no. 8, pp. 944-951, 2009.

[12] K. A. Khalil, H. Fouad, T. Elsarnagawy, and F. N. Almajhdi, "Preparation and characterization of electrospun PLGA/silver composite nanofibers for biomedical applications," International Journal of Electrochemical Science, vol. 8, no. 3, pp. 34833493, 2013.

[13] H. J. Jin, M. O. Hwang, S. Y. Jin, H. L. Kwang, I. Chin, and M. Kim, "Preparation and characterization of electrospun 
poly(L-lactic acid-co-succinic acid-co-1,4-butane diol) fibrous membranes," Macromolecular Research, vol. 13, no. 1, pp. 73-79, 2005.

[14] R. Sridhar, S. Sundarrajan, J. R. Venugopal, R. Ravichandran, and S. Ramakrishna, "Electrospun inorganic and polymer composite nanofibers for biomedical applications," Journal of Biomaterials Science, Polymer Edition, vol. 24, no. 3, pp. 365385, 2013.

[15] T. H. Gilman, "Methods of applying a hydrophilic coating to a substrate, and substrates having a hydrophilic coating," U.S. Patent. no. 0015192 A1, 2012.

[16] D. J. Buckley, D. G. Wildes, W. Lee, and W. B. Griffin, "Materials and processes for bonding acoustically neutral structures for use in ultrasound catheters," U.S. Patent 0256502 A1, 2010.

[17] C. L. Restuccia and C. LoFaro, "Structural composite material with improved acoustic and vibrational damping properties," U.S. Patent. No. 0170746 A1. 2010.

[18] N. L. Le, Y. Wang, and T. S. Chung, "Pebax/POSS mixed matrix membranes for ethanol recovery from aqueous solutions via pervaporation," Journal of Membrane Science, vol. 379, no. 1-2, pp. 174-183, 2011.

[19] E. V. Konyukhova, A. I. Buzin, and Y. K. Godovsky, "Melting of polyether block amide (Pebax): the effect of stretching," Thermochimica Acta, vol. 391, no. 1-2, pp. 271-277, 2002.

[20] C. Cheng, R. Tang, and F. Xi, "Preparation and aggregation of polypseudorotaxane from dendronized poly(methacrylate)poly(ethylene oxide) diblock copolymer and $\alpha$-cyclodextrin," Macromolecular Rapid Communications, vol. 26, no. 9, pp. 744749,2005

[21] Q. T. Nguyen, J. Sublet, D. Langevin et al., " $\mathrm{CO}_{2}$ permeation with Pebax -based membranes for global warming reduction," Membrane Gas Separation, vol. 9, no. 1, pp. 255-277, 2010.

[22] Q. Shi, N. Vitchuli, J. Nowak et al., "Durable antibacterial $\mathrm{Ag} /$ polyacrylonitrile (Ag/PAN) hybrid nanofibers prepared by atmospheric plasma treatment and electrospinning," European Polymer Journal, vol. 47, no. 7, pp. 1402-1409, 2011.

[23] "Microbiology of food and animal feeding stuffs-horizontal method for the enumeration of microorganisms-colony-count technique at $30^{\circ} \mathrm{C}$," ISO 4833.

[24] ISO 22196, "Plastics-measurement of antimicrobial activity on plastics surfaces," 2007.

[25] V. Nafisi and M. B. Hägg, "Development of dual layer of ZIF-8/Pebax-2533 mixed matrix membrane for $\mathrm{CO}_{2}$ capture," Journal of Membrane Science, vol. 459, no. 1, pp. 244-255, 2014.

[26] J. W. Rhim, L. F. Wang, and S. I. Hong, "Preparation and characterization of agar/silver nanoparticles composite films with antimicrobial activity," Food Hydrocolloids, vol. 33, no. 2, pp. 327-335, 2013.

[27] C. Chen, L. Wang, and Y. Huang, "Electrospinning of thermoregulating ultrafine fibers based on polyethylene glycol/cellulose acetate composite," Polymer, vol. 48, no. 18, pp. 5202-5207, 2007.

[28] B. C. Hancock, S. L. Shamblin, and G. Zografi, "Molecular mobility of amorphous pharmaceutical solids below their glass transition temperatures," Pharmaceutical Research, vol. 12, no. 6, pp. 799-806, 1995.

[29] Q. Fu, A. Halim, J. Kim et al., "Highly permeable membrane materials for $\mathrm{CO}_{2}$ capture," Journal of the American Chemical Society, vol. 132, no. 1, pp. 13769-13778, 2013.

[30] O. Akhavan, "Lasting antibacterial activities of $\mathrm{Ag}-\mathrm{TiO}_{2} / \mathrm{Ag} / \mathrm{a}-$ $\mathrm{TiO}_{2}$ nanocomposite thin film photocatalysts under solar light irradiation," Journal of Colloid and Interface Science, vol. 336, no. 1, pp. 117-124, 2009.

[31] O. Akhavan and E. Ghaderi, "Bactericidal effects of Ag nanoparticles immobilized on surface of $\mathrm{SiO}_{2}$ thin film with high concentration," Current Applied Physics, vol. 9, no. 6, pp. 1381$1385,2009$.

[32] S. Zhang, F. Peng, H. Wang, H. Yu, J. Yang, and H. Zhao, "Electrodeposition preparation of Ag loaded N-doped $\mathrm{TiO}_{2}$ nanotube arrays with enhanced visible light photocatalytic performance," Catalysis Communications, vol. 12, no. 8, pp. 689693, 2011.

[33] D. P. Dowling, K. Donnelly, M. L. McConnell, R. Eloy, and M. N. Arnaud, "Deposition of anti-bacterial silver coatings on polymeric substrates," Thin Solid Films, vol. 398-399, pp. 602606, 2001.

[34] Q. Shi, N. Vitchuli, J. Nowak et al., "One-step synthesis of silver nanoparticle-filled nylon 6 nanofibers and their antibacterial properties," Journal of Materials Chemistry, vol. 21, no. 28, pp. 10330-10335, 2011.

[35] A. Celebioglu, Z. Aytac, O. C. Umu, A. Dana, T. Tekinay, and T. Uyar, "One-step synthesis of size-tunable Ag nanoparticles incorporated in electrospun PVA/cyclodextrin nanofibers," Carbohydrate Polymers, vol. 99, no. 2, pp. 808-816, 2014. 

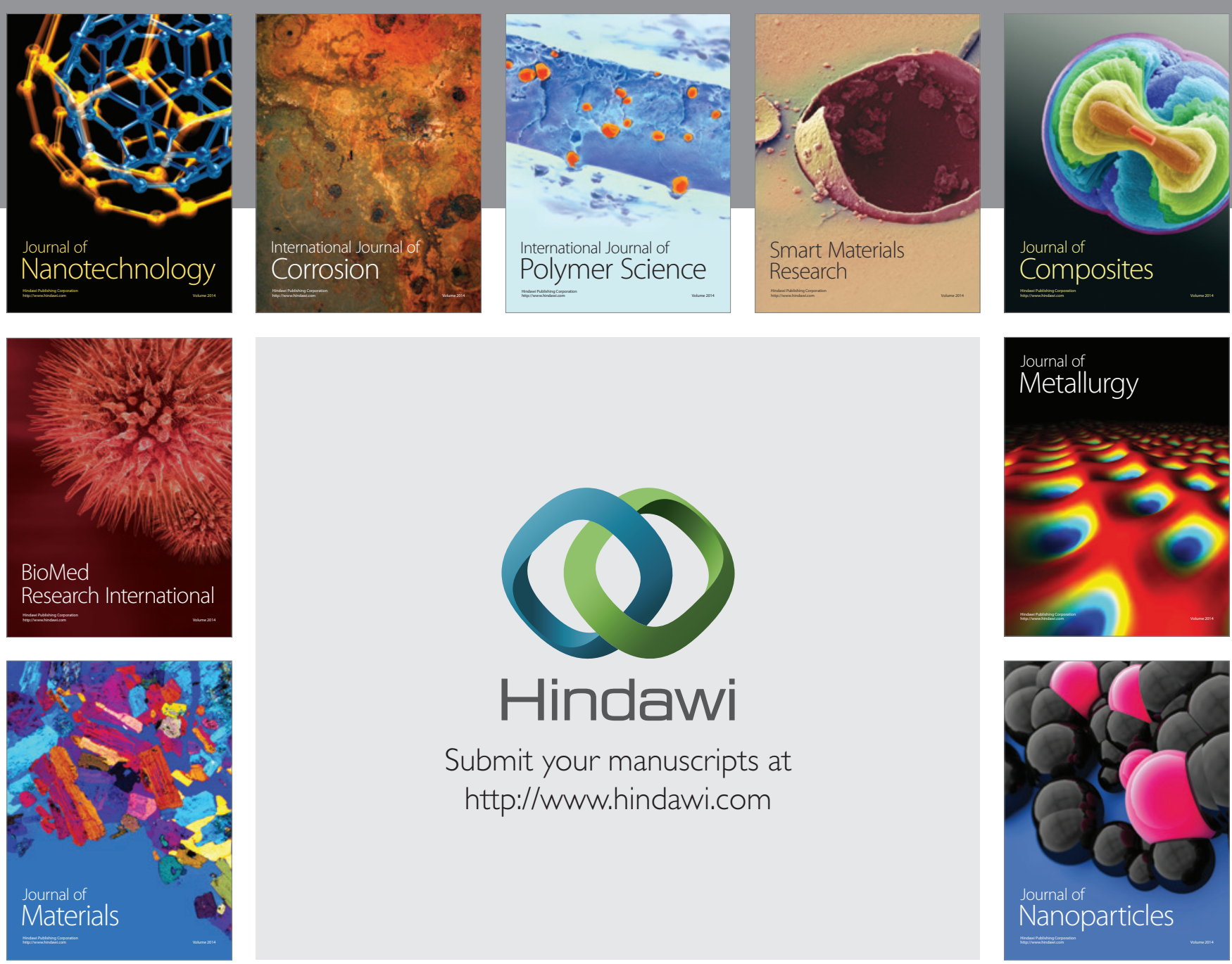

Submit your manuscripts at http://www.hindawi.com
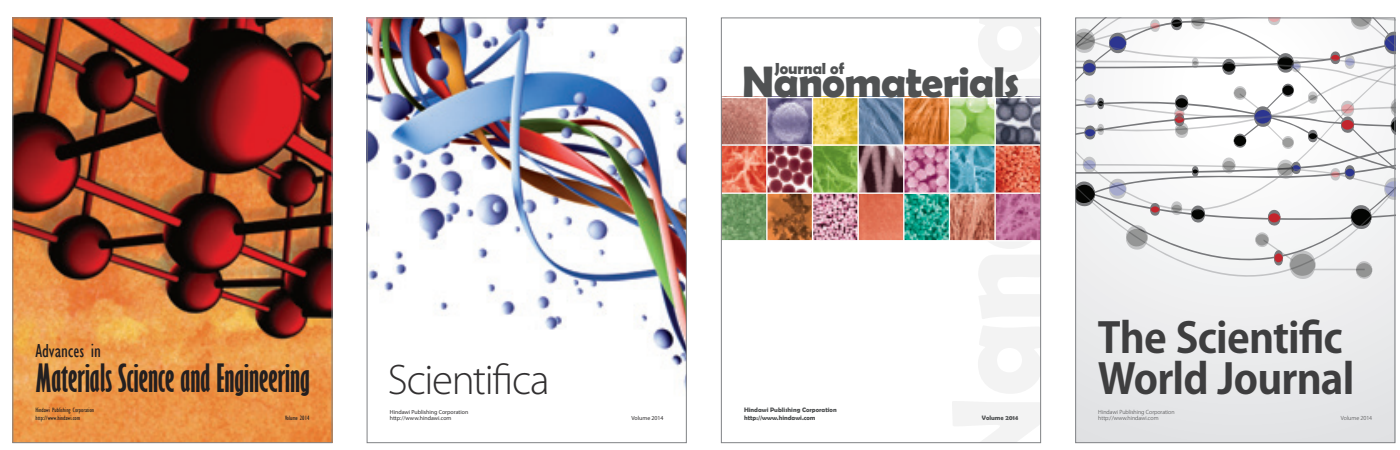

\section{The Scientific World Journal}
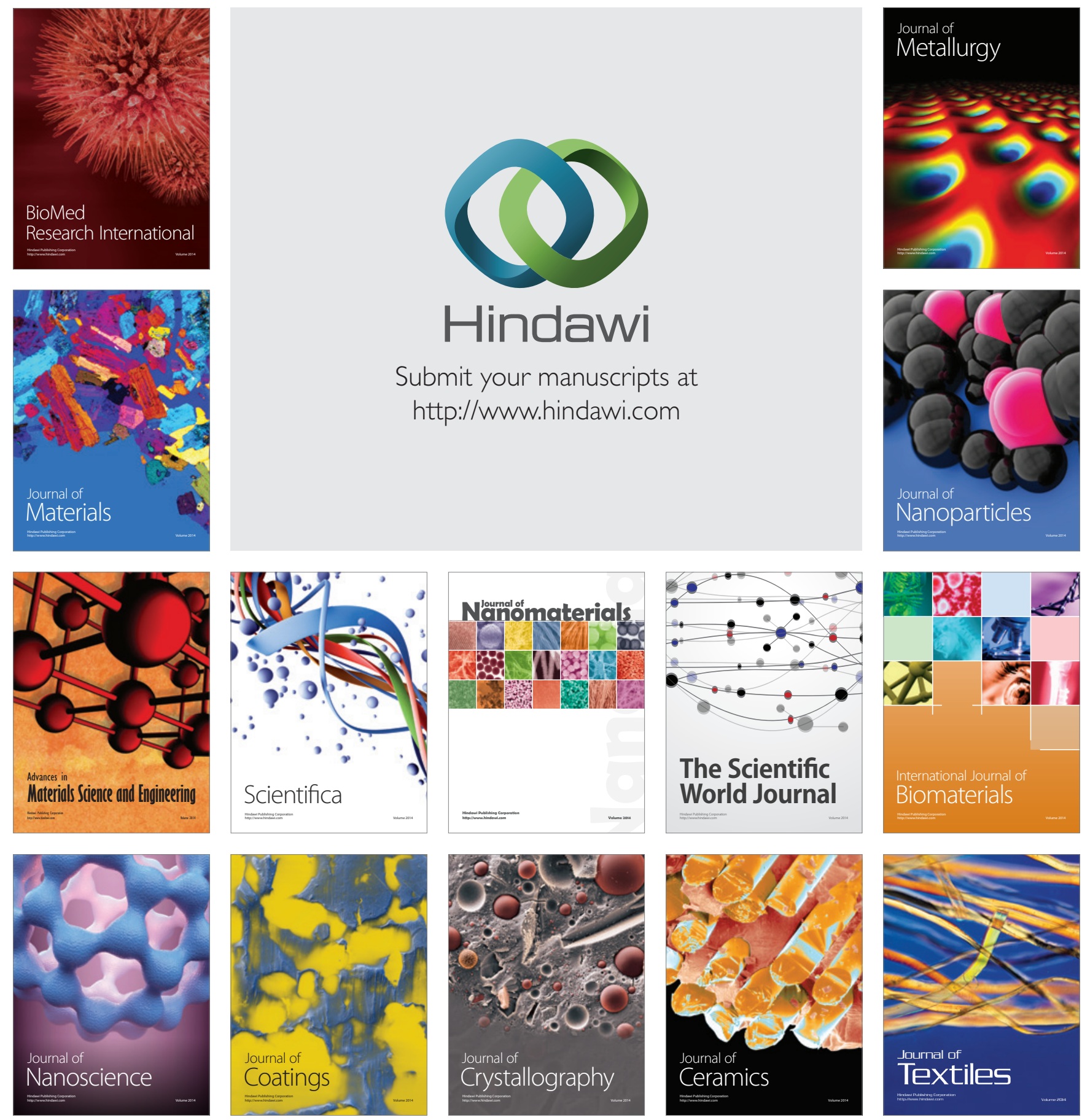